\title{
Register analysis and ESP pedagogy: noun-phrase modification in a corpus of English for Military Navy submariners.
}

\begin{abstract}
Research in Maritime English (ME) has paid no attention to the range of texts and language which Navy submariners are exposed during their training and professional careers. This research looked at Noun Phrase modification patterns in a longitudinal corpus of Submarine English (SE) professional texts in the Cartagena Military Submarine Corpus (CMSC). Using a combination of quantitative and qualitative analyses, we found that SE is characterised by heavy nominal premodification, low adjective premodification, low prepositional phrase postmodification and by the predominant use of appositive nouns in postmodifying slots. These distinctive features of SE call for a register-sensitive pedagogy that unpack these characteristics and present them in context. We argue that the contribution of corpus-linguistics is essential to explore registers which, for different reasons, have not been addressed or described linguistically in the past. Similarly, we maintain that the examination and teaching of NPs is essential to understand current trends in professional writing and communication.
\end{abstract}

Keywords: Military English, Maritime English, Register Analysis, Noun Phrase, Corpus Linguistics, ESP pedagogy. 


\section{1.-Introduction and research context}

Little is known about the range of language registers which the Military are exposed when they are trained in warfare schools in non-English speaking countries. There is, however, a variety of textbooks and materials that address the needs of international forces. Tick (2006) developed an e-learning English Language Teaching (ELT) course based on the NATO Standardized Language Profile (SLP) for the Hungarian Military.Orna-Montesinos (2016) created English language learning materials drawing on a needs analysis of communication practices for the Spanish Armed Forces.This work aimed at developinggeneral English skills and intercultural communication awareness. Generally, NATO language descriptors have been widely used to create contents such as peacekeeping, humanitarian assistance or leadership. Despite these efforts, the analysis of specific training Military registers has played little or no role in the description and pedagogy of English for the Military.

The Spanish Navy Submarine Warfare School trains future submarine crews (officers, petty officers and master seamen). It has a Technical Secretary's office, simulators as well as Weapons, Tactics, Energy and Propulsion departments. At the Submarine Warfare School, the future submariners learn specific specialized subjects, including English as a foreign language, a subject which has traditionally combined general and Maritime English contents. These students are regularly commissioned to NATO 
submarine operations, international underwater manoeuvres, as well as NATO meetings and conferences. A good command of English for these specific tasks is therefore essential. However, existing Maritime English (ME) teaching materials do not cope

with all their communication and field-related needs as ME materials tend to focus on ships and terminology not specific to submarines.

According to Trenkner (2000:7), "ME is the entirety of all those means of the English language which, being advisable for communication within the international maritime community, contribute to the safety of navigation and the facilitation of the seaborne business". ME is studied as a lingua franca used on board and ashore by people working in the maritime field worldwide. It includes not only set languages such as Seaspeak and IMO Standard Phrases, which are used in ship-to-ship, ship-to-shore and shipboard communications regarding the civil world, but also a variety of lexical fields, such as shipbuilding, seamanship, cargo handling, meteorology, marine engineering, electricity and electronics, port operations, marine environment, safety at sea, international rules and regulations, shipping, tourism and history. Unfortunately, the specifics of the English needed by Military Submariners (henceforth Submarine English, SE) is not included in the scope of ME.

We seek to gain a deeper understanding of the language register(s) that the Navy Submariners need to master and use during their training and determine whether this register poses significant pedagogical challenges. We will use noun phrase modification as the main unit of analysis in order to understand the linguistic nature of the register 
that these Submariners are exposed to by examining Noun Phrase complexity. These findings will, in due time, inform a register-driven pedagogic approach which can offer context-sensitive pedagogical solutions to the training Military. This paper looks, consequently, at modification in noun phrases, one of the defining features of written English (Biber\& Clark, 2002; Pastor-Gómez, 2009)in the context of a corpus of texts of relevance for the training of professional Navy submariners.

Section 2 deals with a review of the literature in the areas of ME and corpus linguistics. Section 3 offers the research methodology of our study, while Section 4 includes the results of our research. In Sections 5 and 6, we offer a discussion of our results and a conclusion that incorporates some insights into future research and applications.

\section{2.-Maritime, Submarine English and the role of NP across registers}

\subsection{Introduction}

The notion of register has contributed to our understanding of how communication is mediated by communicative situational factors. Biber et al. (1999) established a corpusdriven comparison of a wealth of linguistic features across four broad registers, namely, academic writing, conversation, news language and fiction, revealing that the frequency distribution of different grammatical features varied systematically. In other words, the lexico-grammatical fabric of language is register sensitive. We use the term register in this paper within the framework established by Biber et al. (1999) and Biber \& Conrad (2009) as a variety of language that can be characterized by both the situation in which it is used and how the language is used. Our research does not compare registers within 
a discipline or specific sections in texts (Swales 1990). Instead, this paper focuses on one register and, specifically, NPs as used in the corpus analysed, their modifiers and their modification types.

Research in premodification in the NP has predominantly focused on the adjective phrase. Quirk et al. (1985) established four different premodification zones: precentral, central, postcentral, and prehead position. Non-gradable adjectives are placed in precentral position, gradable adjectives are situated in central position and participles

and colour adjectives are found in postcentral position. Recent studies show evidence of the increasing use of nouns as premodifiers. Biber\& Clark (2002) observed the recent increase in use of nouns as premodifiers in present day English. Similarly, PastorGómez (2009) found that the number of Noun+ Noun structures is register-sensitive. Postmodification in the NP has also attracted the attention of different researchers.

De Haan (1989) studied postmodifying clauses that occur in the post-head position in NPs. He found that in $85 \%$ of the instances in his corpus were realized by finite relative clauses. Similarly, Berlage (2014) established NP + Prepositional Phrase as the most frequent syntactic structure in her data, followed by the NP+ non-finite clause .

\subsection{Maritime English}

ME is considered as a variety of English used by the maritime community. Its use is strongly recommended for seafarers in their daily routines (Pritchard, 2002; Pritchard 2003). In addition, ME is a mix of different sub domains according to the field or 
subject matter (nautical, logistics, technical, legal, etc.), which makes it a complex register to study (Cole, Pritchard and Trenkner, 2007).The tenor is also very wide, ranging from nautical engineering students, specific shipboard and port speech community to maritime secretaries. ME can be conceptualized as a holistic register with a wide variety of branches of study as well as different contexts of situation.

The first teaching materials on ME were Wavelength (Weeks, 1996), English for Maritime Studies (Blakey, 1987) and Seaspeak Training Manual (Glover, Johnson, Stevens and Weeks, 1998). These studies were pioneers in the development of pedagogic Maritime English materials. The MARCOM report (1998) was also an

important didactic work on the impact of multicultural and multilingual crews on maritime communication. This report indicated that one single ME syllabus would not possibly meet all the needs of ME users.

In response to extended demand, by seafarers worldwide to reduce the problem of language barriers at sea and avoid misunderstandings, the Standard Marine Communication Phrases (SMCP) were published by the International Maritime Organization (IMO, 2001). This was a set of key phrases in English that comprised external communication phrases (ship to ship \&ship to shore communication and on board communication phrases. The standardised form of maritime communications (SMCP 2001) was further integrated in to the IMO model course 3.17 in 2009 on an international ME syllabus. Similarly, Cole and Trenker ( 2012) emphasized the two-fold nature of Maritime English, first as a linguistic branch of applied linguistics and, second, as a subject to be taught with a communicative methodology. They also 
developed a tool called " The Yardstick"(2009), as anew Maritime English proficiency assessing tool to evaluate students' knowledge on ME.

But, even ME descriptions as comprehensive as the one provided by Bocanegra (2013:1) fail to include areas such as sea tourism, naval engineering or, to name just a few, communication in the Navy: "ME subsumes five different sub varieties according to the specific purpose they serve within the maritime context: English for navigation and maritime communications, English for maritime commerce, English for maritime law, English for marine engineering, and English for shipbuilding".

The sub-varieties or ME branches above mentioned respond to different communication needs, medium (written or oral) and channels (users and receivers). Del Pozo Triviño (2011) considers English for Maritime Law and commerce as a sub-variety or sub-genre that includes written documents such as Charter Parties, Bills of Lading, sale contracts, shipbuilding contracts, or maritime insurances. Similarly, Kluijven (2003) pays special attention to the Standardized forms of maritime communication, both inter-ship and intra-ship, when studying English for Navigation.

The nature and wide scope of ME make it certainly challenging for language practitioners in the Military context to adopt a generic ME approach for the learning and teaching of English as Military uses, and in particular the range of communicative needs of Naval submariners, present further challenges for ME researchers and call for a further analysis of the register which professionals in the field are exposed during their training and careers.

\subsection{Noun phrases in ESP}


Research in NP complexity has focused either on either academic/scientific English or on specific domain areas of English for Specific Purposes. In general terms, the first strand of studies (Biber and Gray 2011; Hutter 2015; Pastor-Gomez 2009) has described discourse that exhibits a higher number of nominal premodifiers. The second strand has revealed that ESP reveals a preference for attribute adjectives as premodifiers (LasoMartín 2006; Crayton Walker 2011).

Quantitative register analyses (Biber\& Conrad, 2009) have shed light on the role and the characteristics of nouns and noun phrases across different types of texts. These studies highlight the fact that the frequency and distribution of linguistic features are extremely sensitive to the functions performed by the texts where they are used, which makes the case for detailed analysis and research of registers which are of interest to specific groups of users. Biber et al. (1999) found that, when compared with conversation and fiction registers, noun modification is exceptionally common in academic writing, and that about $60 \%$ of all nouns are premodified, postmodified or both. For the authors, this high degree of modification can be explained by the need to specify complex meaning.

While academic and scientific English have attracted an enormous amount of attention, other specific or professional registers have received less or no attention. Biber and Gray (2011) analysed the development of nouns as nominal premodifiers and prepositional phrases as nominal postmodifiers in a corpus of academic research writing (compared to other registers such as fiction, newspaper reportage and conversation) and found that academic writing is more nominal than verbal. Their research provided plenty of evidence on how meaning in academic English tends to be condensed into noun phrases rather than being expressed clausally. Similarly, Parkinson and Musgrave 
(2014) confirmed these findings, suggesting the need for a focus on a corpus of English for Academic Purposes (EAP) as a source for classroom language work on noun modification.

Hutter, J.A (2015) tested Biber et al.'s (1999) findings by examining a corpus of research articles from the fields of applied linguistics and language teaching. She studied the connection between IMRD article sections (Introduction, Methods, Results, Discussion) and six different types of noun modification: relative clauses, ing-clause postmodifiers, ed-clause postmodifiers, prepositional postmodifiers, premodifying nouns, and attributive adjectives. She found that noun modification was not uniform across the four sections of research papers. Significant differences were found in the rates of use for attributive adjectives, premodifying nouns, and prepositional phrase postmodifiers. There were no significant differences between sections for relative clauses, ing-clause postmodifiers, or ed- clause postmodifiers. Hutter, J.A (2015: p.9) showed that the most common noun modification patterns, that is, "premodifying noun only", "attributive adjective" and "prepositional phrase postmodifiers", were consistent across sections. All in all, modification occurred in $63 \%$ of the nouns in the introduction sections while only in $48 \%$ of the nouns in the methods sections. Pastor-Gómez (2009) found a high frequency of nouns as premodifiers in NP structures in contemporary English in corpora of written and spoken English (reportage, science, editorials, fiction and belles letters).Her corpus showed that journalistic language contained the highest number of nominal premodifiers.

The number of $\mathrm{N}+\mathrm{N}$ structures was higher in reportages, which amounted to $31.11 \%$ of all nominal premodifiers found in the data, $20.29 \%$ in science texts. 
While previous research has examined the use of technical vocabulary in specialized discourse (Chung \& Nation, 2003), other researchers have focused on specific professional discourse by looking beyond the word as a unit of analysis. Laso-Martín (2009) carried out a corpus-based study of the phraseological behaviour of abstract nouns in medical English extracted from the Health Science Corpus (HSC). It was found that the collocational patterns of the noun contribution in her corpus was associated with specific grammatical patterns. The noun analysed showed a preference for attributive modifying position, together with the fact that it was usually premodified by relational and topical classifying adjectives. The author argued for the necessity of this type of study for future collocation teaching materials in health sciences.

The language of business has also received some attention. Within the scope of noun modification, Walker (2011) showed how a corpus-based study of the factors which influence collocation can help in the teaching of this area of ESP. The author claimed that by studying collocations associated with synonyms it is possible to identify slight but important differences. She found that the noun process was frequently associated with an adjective + noun frame (e.g., long and difficult process). The noun procedure was associated with adjectival collocates which included items such as normal, standard and correct. The fact that the noun procedure was used in a more prescriptive way than the noun process depending on their premodifiers exemplifies the contributions of corpus analysis to ESP pedagogy.

Walker (2011) stressed the contribution of attributive adjectives to the creation of either negative or positive semantic prosody of nouns. 
The analysis of a corpus of texts of relevance for the training of professional users (Gavioli, 2005), in our case Navy submariners, is essential in order to contribute to both the understanding of a register and its pedagogy. Given the lack of research in military professional registers in ME, this paper will examine the extent to which noun phrase modification presents distinctive features to those outlined in previous research. We will adopt a corpus-driven approach (Tognini-Bonelli,2001) and, subsequently, no a-priori assumptions on the frequency and importance of the lexical items which integrate our data will be made. The research questions in this paper are the following:

(1) Does Submarine English exhibit distinct Noun Phrase complexity features? If so, which are these?

(2) Which areas of the NP behaviour analysed, if any, are of interest to SE language education? 


\section{Methodology}

In the following paragraphs, we will give further details on how the Cartagena Military Submarine Corpus was compiled and how the analysis of complexity in NPs was carried out.

\subsection{The Cartagena Military Submarine Corpus (CMSC)}

Our SE register study was carried out through the analysis of a representative corpus of the range of texts that navy submariners are exposed during their training and future careers in the Spanish Navy Submarine Warfare School. Given the lack of available corpora in this area, we decided to compile a corpus of Naval Submarine English (NSE) of relevance to the professional needs of those in the aforementioned school. As the textbooks and reports written in English that are used at this School are classified by the Spanish Defence Authority, it was not possible to gather a corpus of such texts. We focused instead on the unclassified material curated by the Ministry of Defence and which is the primary source of professional information in English for all Spanish Navy submariners. This official publication is distributed in printed form and is made up of selected articles from fourteen widely known magazines/journals in the Navy: Naval Forces, Jane's Defence Weekly, Jane's Navy International, Armed Forces, the submarine review, Proceeding Naval Magazine, Ocean system Under sea Enterprise, News Daily, Jane's International Defence Review, Submarine News Daily, Military technology, Undersea warfare and The Swedish Sub Centennial. Figure 1 shows the breakdown of texts per year and source included in our corpus: 


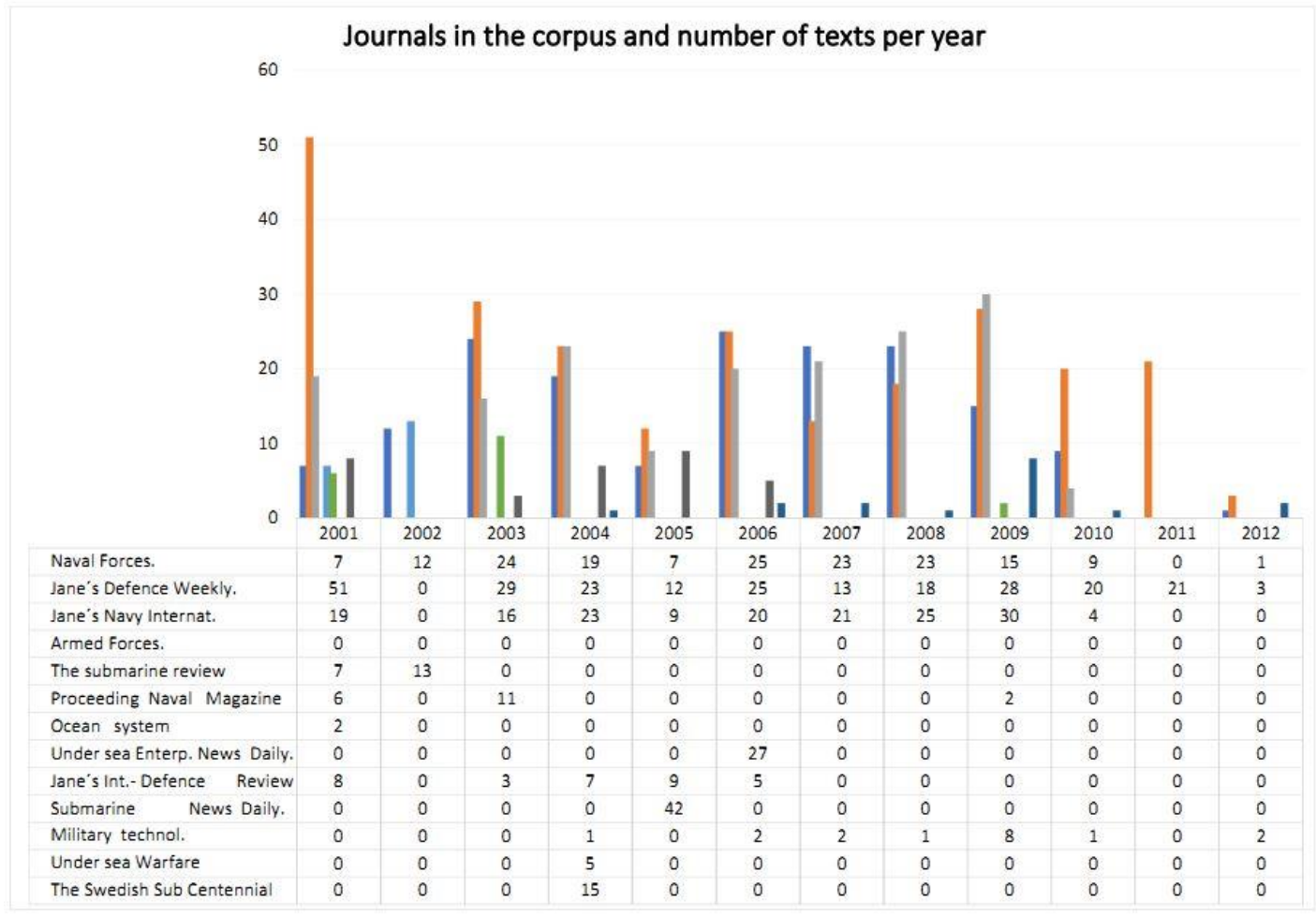

Figure 1. Journal sources of the Cartagena Military Submarine Corpus (CMSC).

The Cartagena Military Submarine Corpus (CMSC) is made up of 822,755 words and comprises 12 years of curated texts published in a wide range of different professional magazines/journals published by either professional associations such as the U.S. Naval Institute(Proceeding Naval Magazine) or publishers specialized in military issues such as the Mönch Publishing Group (Military Technology).Generally, these texts address a professional readership that is interested in advancing their technical and scientific understanding of different issues critical to submarines and naval technology. It contains a total of 952 different texts that are regularly read by trainees and used by language instructors for language learning purposes. Most of these texts were originally 
published in the US so this is the variety that is mostly represented in our data. The printed texts were first OCR-ed (Optical character Recognition) and their consistency manually checked by the researchers and collaborators at UPCT ( Polytechnic

University of Cartagena, Spain). The corpus was later POS tagged and queried on Sketch Engine (Kilgarriff et al., 2014).

We first obtained the most frequent nouns in the corpus and selected the ten most frequent nouns in this list to carry our examination of NP modification.

Table 1 offers the 50 most frequent lemmas in our corpus and their raw frequency:

\begin{tabular}{|c|c|c|c|c|c|}
\hline $\begin{array}{l}\text { Frequency } \\
\text { rank }\end{array}$ & Lemma & Raw Freq & $\begin{array}{l}\text { Frequency } \\
\text { rank }\end{array}$ & Lemma & Raw Freq \\
\hline 1 & the & 57184 & 26 & its & 2390 \\
\hline 2 & be & 28182 & 27 & not & 2361 \\
\hline 3 & and & 24742 & 28 & can & 2219 \\
\hline 4 & of & 24320 & 29 & use & 2140 \\
\hline 5 & to & 21720 & 30 & also & 2087 \\
\hline 6 & $\mathrm{a}$ & 17473 & 31 & new & 1998 \\
\hline 7 & in & 16889 & 32 & design & $\begin{array}{c}1979(1342 \\
\text { as } \mathrm{N})\end{array}$ \\
\hline 8 & for & 9344 & 33 & but & 1859 \\
\hline 9 & have & 7515 & 34 & ship & 1802 \\
\hline 10 & submarine & 7449 & 35 & 's & 1780 \\
\hline 11 & with & 6606 & 36 & two & 1702 \\
\hline
\end{tabular}




\begin{tabular}{|c|c|c|c|c|c|}
\hline 12 & that & 6464 & 37 & say & 1697 \\
\hline 13 & on & 5225 & 38 & year & 1642 \\
\hline 14 & as & 5188 & 39 & more & 1631 \\
\hline 15 & by & 4733 & 40 & boat & 1586 \\
\hline 16 & it & 3921 & 41 & would & 1557 \\
\hline 17 & will & 3913 & 42 & force & $1537(1417$ \\
\hline 18 & at & 3897 & 43 & capability & 1529 \\
\hline 19 & an & 3858 & 44 & we & 1522 \\
\hline 20 & system & 3796 & 45 & class & 1497 \\
\hline 21 & from & 3664 & 46 & missile & 1489 \\
\hline 22 & this & 3363 & 47 & first & 1415 \\
\hline 23 & Navy & 2709 & 48 & torpedo & $\begin{array}{c}1410(1359 \\
\text { as } \mathrm{N})\end{array}$ \\
\hline 24 & or & 2603 & 49 & other & 1406 \\
\hline 25 & which & 2577 & 50 & their & 1406 \\
\hline
\end{tabular}

Table 1. 50 most frequent lemmas in the CMSC.

Based on the raw frequency in Table 1, ten Nouns (submarine, system, Navy, ship, boat, force, capability, class, missile, torpedo) were selected for our study on NP complexity. Year, $35^{\text {th }}$ most frequent lemma, was not included in the list given its time meaning and potential less interesting role in the description of the CMSC. Instead we included the 
next most frequent noun, torpedo. We used the sample feature in Sketch Engine to generate a sample of 500 concordance lines, fifty for each of the ten nouns. This feature randomly selects a certain number of lines and guarantees a representative sample of the whole concordance.

These randomly-generated lines were annotated individually for the following features (Biber et al., 1999): presence/absence of modification, type of modification, type of postmodification and co-concurrence of pre and postmodification.

In particular, we examined the following: adjectives, participles, nouns and adverbs as premodifiers, and relative clauses, to-infinite, ing, ed clauses, prepositional phrases, appositive noun phrases, adjective phrases and adverbs as postmodifiers.

\section{Results.}

In this section, we offer the results of the analysis of noun phrase modification across the ten nouns in this study.

\subsection{Absence of premodification or postmodification in noun phrases.}


As Figure1shows, $38.4 \%$ of the nouns analysed were not premodified. However, there is a considerable degree of variation across the 10 nouns analysed.

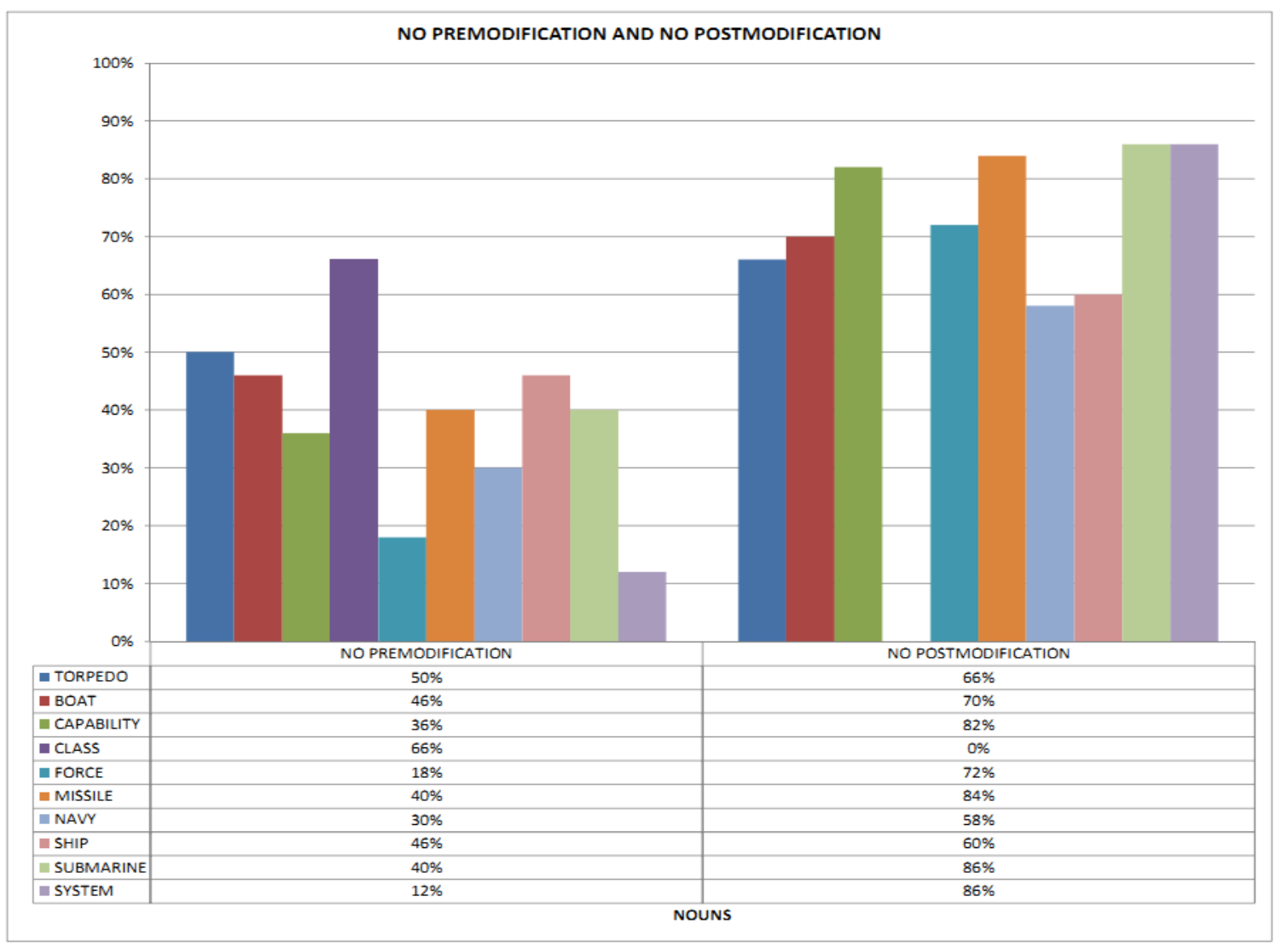

17

Noguera, Y. \& Pérez-Paredes, P. (2018) Register analysis and ESP pedagogy: noun-phrase modification in a corpus of English for Military Navy submariners. English for Specific Purposes, https://doi.org/10.1016/j.esp.2018.06.002 
Figure 2. Percentages of no-premodification and no-postmodification in CMSC.

The noun class (1) was not premodified in $66 \%$ of its occurrences, followed by the noun torpedo (2), not premodified in $50 \%$ of the occurrences, and the nouns boat (3), ship (4) and submarine (5), where over $40 \%$ of their occurrences were not premodified in any way. In contrast, the nouns (6) force and (7) system exhibited the lowest percentage of no-premodification, $18 \%$ and $12 \%$, respectively. The following concordance lines from our corpus illustrate the above. In brackets, the year in which the text was published and distributed by the Spanish Defence Authority:

(1) (CMSC-2006) Some classes incorporate two special radars.

(2) (CMSC-2008) The torpedo incorporates a homing system of active-passive type.

(3) (CMSC-2002) This tempo is running our boats and possibly our people out of gas.

(4) (CMSC -2000) So why doesn't the Navy routinely court-martial commanding officers when their ships are sunk?

(5) (CMSC -2002) The submarine also has space for six additional fold-down bunks for special operations crew.

(6) (CMSC-2010) The forces are also deciding how to run electronic-warfare and cyber operations alongside each other.

(7) (CMSC-2008) Both systems enable the conventional submarine to stay submerged independent of outer air for up to 2-3 weeks.

$66.4 \%$ of the nouns analysed evidenced no postmodification whatsoever. Here, the degree of variation is also high. Nouns such as submarine (8), system (9), missile (10) 
and capability (11) are not postmodified in over $80 \%$ of their occurrences, while boat (12) and force (13) are not postmodified in $70 \%$ and $72 \%$ of their occurrences, respectively. Class (14) showed no instance of postmodification at all.

(8) (CMSC-2004) The submarine is divided into two compartments and there is access to the rescue sphere from both sides.

(9) (CMSC- 2002) "The propulsion system will be of a new design," he said.

(10) (CMSC-2002) The missile would exploit a wide variety of pay-loads developed to support ground forces.

(11) (CMSC- 2010) Airborne Surveillance capability is currently hosted by the Mk7 helicopter.

(12) (CMSC- 2002) This boat will not be known until she is reopened.

(13) (CMSC-2010) The forces are also deciding how to run electronic-warfare and cyber operations alongside each other.

(14) (CMSC- 2005) Seawolf class is the first in the US to be fitted with fully shrouded propulsion.

\subsection{Premodification in noun phrases.}

Our results show that $62.6 \%$ of the occurrences in this study displayed premodification. Nouns were attested as the most common type of premodifiers as $58.7 \%$ of the nouns were premodified this way. This is shown below with the nouns class, missile and capability: 
(15) (CMSC- 2011)-Work on the Halifax class will be completed at Halifax Shipyards in Nova Scotia.

(16) (CMSC-2007) The cruise missile is likely being employed within new forms of Cnets.

(17) (CMSC- 2006) Pressure capability is a 600m depth capability and a 72-hour time to first rescue (TTFR).

Adjectives (18) premodified nouns in $33.6 \%$ of the occurrences and were the second most frequent type of premodifier. Other premodifier categories were less frequent: -ing clauses (19) were found in $3.8 \%$ of the noun phrases, past particles (20) in $2.1 \%$, while adverb phrases (21) in only $1 \%$.

(18) (CMSC-2006) One of the latest customers for ex USN Orions is the Indian Navy.

(19) (CMSC-2007) The programme also extends to the Principe De Asturias-class aircraft carrier and training vessels, including the training ship Juan Sebastian de Elcano.

(20) (CMSC-2000) Armed forces had bad communications with the sub for initial confusion over the extent of the fire.

(21) (CMSC-2002) The main capability for anti-shipping, reconnaissance and covert operations is provided by the HN's sub-marine service.

Nouns used as premodifiers occurred very frequently in the ten nouns studied: class and missile showed the highest percentage of noun premodification with $94.12 \%$ and Noguera, Y. \& Pérez-Paredes, P. (2018) Register analysis and ESP pedagogy: noun-phrase modification in a corpus of English for Military Navy submariners. English for Specific Purposes, https://doi.org/10.1016/j.esp.2018.06.002 
$83.33 \%$ respectively, followed by system and capability with $70 \%$, boat, $59.26 \%$ and torpedo, $32 \%$. The range of meanings expressed by pre-modifying nouns refer to intangible nouns, for example attack boat, pressure capability or enemy force, followed closely by tangible nouns such as rubber boat, ships capability and harpoon missile. The rest of the categories such as title nouns, specific places and general locations were not fully-represented in this study and just a few instances could be found such as in Comandanti class (title noun) and Singapore Navy (specific place).

The use of noun phrases with multiple pre-modifying nouns was not rare in our dataset. While three and even four-noun sequences occurred in eight nouns, Navy and torpedo appeared with no multiple premodification. System (22) is the noun with the highest percentage of multiple premodification in $12 \%$ of the instances analysed, followed by the nouns boat (23) and missile (24) with $6 \%$ both. The nouns submarine (25) and capability (26) were premodified by multiple nouns in $2 \%$ of the instances examined. Figure 3 below offers a detailed breakdown of our results.

(22) (CMSC-2008) This weapon has been designed from the start to have a target acquisition system, namely the ASTRA.

(23) (CMSC-2000) The Los Angeles-class attack boats provided a 33kbs bi-directional transfer rate using the so-called 'asymmetric UHF' mode. 
(24) (CMSC-2004) Lockheed Martin is the only company to have integrated the Tomahawk Land Attack Missile with a pitch.

(25) (CMSC-2010) The Agosta 90 class submarine is currently being operated.

(26) (CMSC-2008) Do-228 was donated and was the heart of the airborne surveillance capability.

(27) (CMSC-2007) The ROKN current submarine rescue ship — "Chong Haejin" was commissioned in March 1997. 


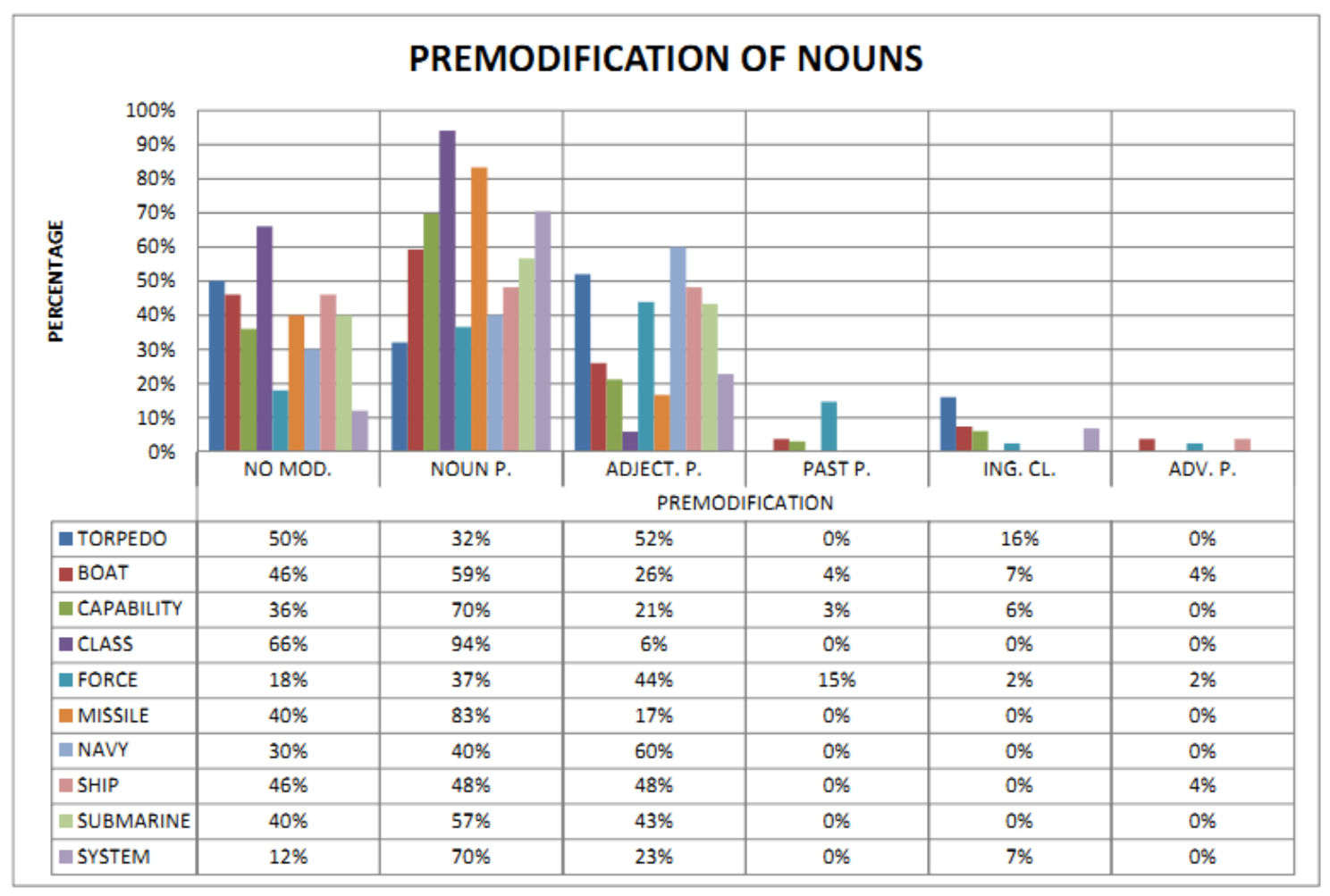

Figure3.Percentages of premodification types in NPs in the CMSC

In our dataset, nouns premodified by adjectives were less common than those premodified by nouns. Again, a high degree of variation was found in the corpus.

Navy was premodified by adjectives in $60 \%$ of its occurrences. In $52 \%$ of its occurrences, torpedo was premodified by adjectives, whereas submarine and ship displayed adjectival premodification in $40 \%$ of the concordances examined. The lowest frequency of adjectival premodification was exhibited by the nouns missile and class with $16.67 \%$ and $5.88 \%$, respectively. Examples (28) to (30) show instances of nouns that display a high percentage of adjectival premodification.

(28a) (CMSC-2010) The Italian Navy ordered the second batch (two boats) of its TODARO class (Type 212A) in April 2008. 
(28b) (CMSC-2008) Hellenic Navy is an industry whose source was close to the programme.

(29) (CMSC-2007) Norway withdrew from any other contemporary submarine programme.

(30) (CMSC -2009) The new ship greatly updates the underwater survey capability of the RTN.

According to Biber et al. (1999), attributive adjectives can be grouped into two semantic categories: descriptors and classifiers. The first describe attributes of the head noun, including physical characteristics, evaluations and emotional states. Classifiers delimit the reference of the head noun identifying the category of the noun and are not gradable. In our study, there are instances of both categories: Descriptors are found in old /elderly boat, new /broad capability, silent / powerful force, new ships, contemporary / new submarine, heavyweight torpedo, etc...whereas classifier adjectives were found in particular/ final boat, current /conventional/special / silent force or diesel/electrical/nuclear boat, maritime/intellectual capability. Some nouns seemed to attract one type of attribute.

The noun Navy, for example, exhibited attributive adjectives within the semantic category of classifiers in all of its occurrences (Spanish navy, German navy, Polish navy...). Other nouns, however, presented more variation. 
Classifier adjectives were used as premodifiers in the noun submarine in $80 \%$ of the concordance lines analysed (nuclear/electric submarine), whereas descriptors were found as premodifiers in the noun torpedo only in $40 \%$ of the instances examined (new/old/heavyweight torpedo).

Past participles, ing-clauses and adverb phrases premodifiers displayed lower frequencies when compared to noun and adjective premodifiers. The noun force showed the highest number of occurrences of past participles as premodifiers in $14 \%$ of the concordances examined, followed by boat and capability with $3.7 \%$ and $3.03 \%$, respectively. Similarly, ing-clauses as premodifiers occurred in a particularly low frequency, ranging from $16 \%$ with the noun torpedo to $2.44 \%$ with the noun force. Adverb phrases are relatively rare as premodifiers in our study with $3.70 \%$ just in the nouns boat and ship. Some of these instances are shown below:

(31) (CMSC-2002) The armed forces have been promised a degree of situational awareness, or common operational picture.

(32) (CMSC-2004) They yield the estimated forces acting on each point of the hull and appendages.

(33) (CMSC-2007) The British torpedo is practically designed to deceive active and passive homing torpedoes.

(34) (CMSC-2009) They force the future ships and new frigates for the navy that would be based on the hull design of the US Coast Guard. 
Some nominal premodifiers included both compounds formed with -ed particles as well as compounds formed with -ing participles. Noun-participle compounds were also used to express some concrete meanings combining nouns that referred to physical entities

with participles expressing tangible actions (e.g. single-crewed boat, wire-guided torpedo, fire-extinguishing system, etc...).Other compounds were formed with the prefix "self" as in self-defence system.

\subsection{Postmodification in Noun Phrases.}

Contrary to what is common in most registers (Biber et al., 2011); prepositional phrases were not the most common type of postmodifiers in our dataset. Prepositional phrases occurred in $29.3 \%$ of the nouns examined whereas nouns occurred in $39 \%$ of them (see Figure 4 below). 


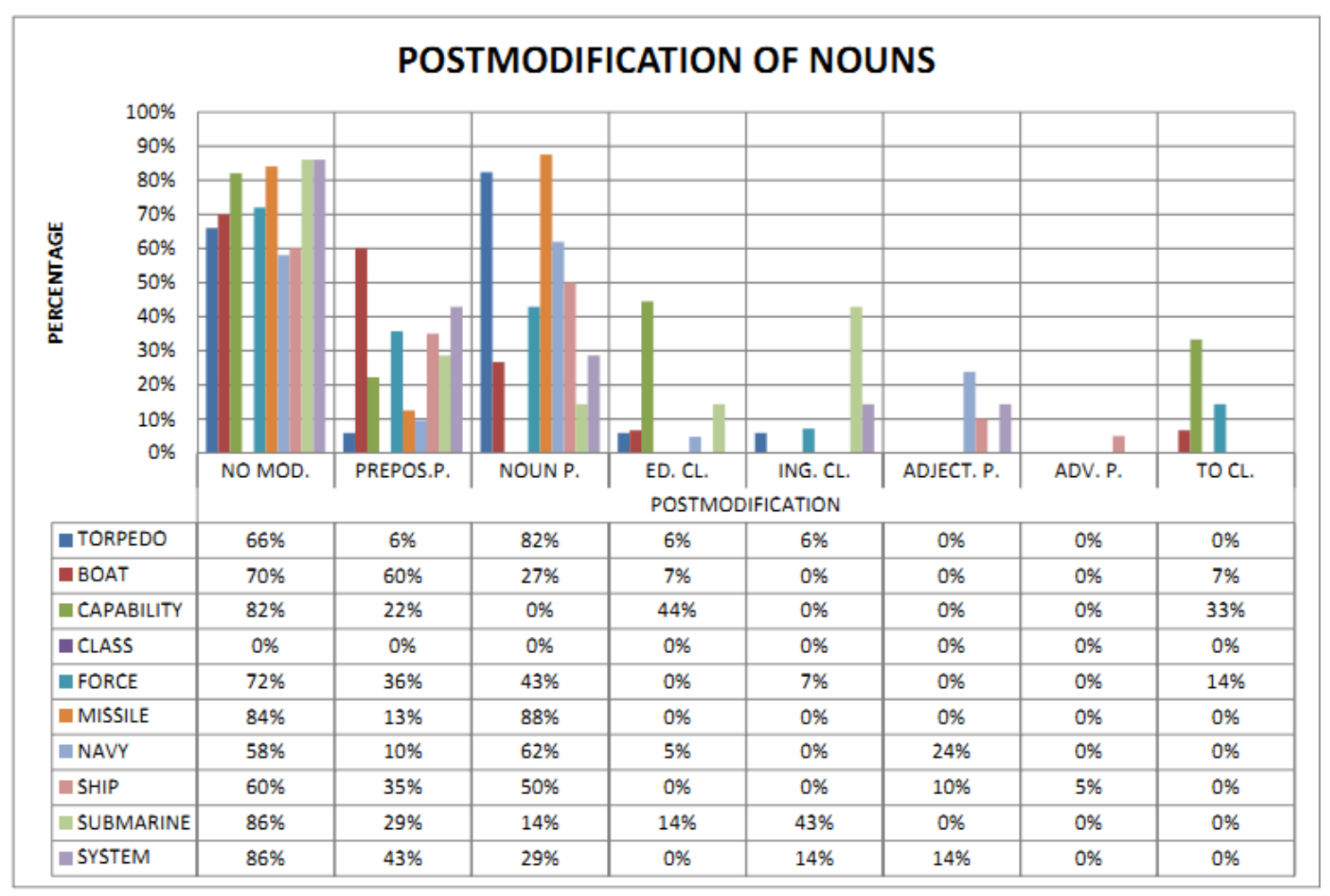

Figure 4. Percentages of postmodification types in NPs in the CMSC.

The two nouns most frequently postmodified by prepositional phrases were boat and system, in $60 \%$ and $42.86 \%$ of the occurrences, respectively. There is a wide range of prepositions that function as the head of prepositional phrases modifying nouns. In our corpus, the prepositions in and of are the most common heads (35 and 36).

(35) (CMSC-2011) A seventh boat in the class would be built.

(36) (CMSC-2007) The first-class boat of a highly sophisticated new Class 214.

Noun phrases as post-modifiers are very frequent in nouns such as missile, $87 \%$ of the occurrences, torpedo, $82 \%$, or navy in $60 \%$ of the concordance lines analysed. These postmodifying noun slots provide opportunities for technical and specific acronyms such as the following: 
(37) (CMSC-2004) Submarine-launched cruise missiles (SLCMS) which may be carried by at least two tugs.

(38) (CMSC-2004) There are many counter- measure system design issues including Torpedo DCL.

Not surprisingly, adjectives as postmodifiers are rare in this corpus, except after compound indefinite pronouns and some fixed expressions. In our study, postposed adjectives play a clarifying rather that descriptive role, as these examples illustrate: navy international, ships operational, ships underway. The noun navy displays the highest percentage of adjectives as postposed modifiers with 23.8\%. Biber et al. (2002) showed that nouns can also be modified by non-finite clauses such as ing-clauses, ed-clauses (also called participle clauses) and to-clauses (infinitive clause). However, in our study we found a similar overall frequency of ed/ing clauses, $7.60 \%$ and $7.01 \%$ respectively.

Ing-clauses exhibit their highest occurrences in the noun submarine, $42.86 \%$, and the lowest, 5.88\%. in torpedo. In the following examples, the head nouns are shown postmodified by these clauses:

(39) (CMSC-2005) In Cold War missions, submarines snooping on Soviet signals would come back reporting antenna time.

(40) (CMSC-2005) Surveillance capabilities of a submarine operating at depth in coordinated anti-submarine warfare operations to achieve undersea dominance. 
To-clauses are infrequent as they were only found in $5.42 \%$ of the concordance lines examined. The noun capability displays the highest percentage observed, in $33 \%$ of the occurrences:

(41) (CMSC-2008) There is a capability to engage a variety of anti-ship missiles and aircraft to support self-defence.

(42) (CMSC-2006) Capability to launch unmanned underwater vehicles (UUV) and unmanned Aerial Vehicles (UAV) from two launch tubes, again depending on overall configuration;

The noun ship is the only noun postmodified by adverbs in 5\% of the occurrences. Most of the adverbs here are examples of locative adverbs :

(43) (CMSC-2004) The submarine was mapping out the seafloor ship nearby.

(44) (CMSC-2002) The sonar pings of the destroyer chases the ship below.

\section{Discussion}

This paper examines noun modification in the Cartagena Military Submarine Corpus (CMSC), a corpus of texts curated by the Spanish Defence Authority from 2000 to 2012 and used by Navy submariners at the Spanish Navy Submarine Warfare School as their main non-classified source of information. In what follows, we will discuss some linguistic and pedagogic aspects of our findings. We will discuss the most distinctive features of the register represented in the CMSC in the context of NP modification, and we will outline a series of implications for the pedagogic use of our findings. 
5.1. Does Submarine English exhibit distinct Noun Phrase complexity features? If so, which are these?

Our research found that $61.6 \%$ of the nouns analysed were premodified and that $33.6 \%$ were postmodified. Nouns account for almost $40 \%$ of all premodifiers in news and $30 \%$ of all premodifiers in academic writing, whereas Prepositional phrases make up 65-80\% of all postmodifiers in all registers, and appositive noun phrases account for over $15 \%$ of all postmodifiers in news and academic prose (Biber et al, 1999).

Nouns were attested as the most common type of premodifiers in $58.7 \%$ of the instances analysed, whereas adjectives were the second most frequent type of premodifiers in $33.6 \%$ of the instances. Our findings suggest that the NPs in the CMSC displayed a distinctive premodifying behaviour when compared to the findings in Biber\& Clark (2011), Laso-Martín (2006) and Crayton (2011), who claimed that common adjectives are the most common category of premodifiers across all registers.

In our study, most attributive adjectives used as premodifiers were classifiers, which confirms previous findings in news and academic prose registers.

No more than two adjectives were found together as premodifiers in the nouns analysed. Our research also confirms the findings in Pastor-Gomez's corpus study (2009), where the highest percentage of nominal premodifiers was found in non-narrative registers (ranging from $31 \%$ in reportage to $20 \%$ in editorials and science). We may argue that the even higher presence of premodification in the CMSC confirms Varantola's (1993) findings that premodifiers, unlike postmodifiers, provide nouns with a status of 
permanence (generating a normative or universal perspective), a requirement for trained submariners in identifying and understanding the complexities of submarine warfare.

However, a heavy reliance on premodification poses extraordinary difficulties to language learners. This condensed typology of premodifiers can confuse learners and provoke some problems of interpretation for non-native students ( Biber \& Gray, 2016). Furthermore, in our special technical register it can create even some misunderstandings. That is the main reason why we consider worth-revising it even for didactic purposes.

In the English grammar, there is no semantic explicit code to set up the relationship between premodifying nouns and heads (Biber et al., 1999), that is, this relationship must be inferred. Biber \& Gray (2016) discussed some possible meaning relations, such as 'specific places', 'tangible', and 'intangible', and claimed that the categories of many noun-noun sequences overlap. In our research, the greatest range of meanings expressed by pre-modifying nouns referred to tangible nouns. As expected from the technical nature of our corpus, the most frequent noun, submarine, belongs to the tangible category, but when premodified by nouns, these can provoke certain overlap or lack of categorization, as it can be observed in attack submarine. In this example, the tangible noun submarine may be understood as being premodified either by (1) the intangible noun attack or (2) by a noun that derives the verb attack. It is really difficult, if not impossible at all, to determine the exact nature of this $\mathrm{N}+\mathrm{N}$ sequence, hence Biber \&Gray's (2016) remark that that overlapping semantic categories are in place in this 
type of sequence. What it seems clear, it is the fact that members of this community of experts have all a common, shared understanding of the external referent which is being talked about. We cannot say the same of the novice reader (Biber \& Gray, 2016), who will need to acquire a better understanding of the external referent being alluded in the corpus.

In this sense, the process of acquiring the jargon of the community of experts involves not only the acquisition of specialised knowledge and vocabulary, but the understanding of how experts represent the artefacts that shape up their conversations.

Biber \& Conrad (2009) claimed that in contemporary English almost any noun could be used freely as a pre-modifier of another head noun, including an increasing number of noun phrases with multiple pre-modifying nouns. In our corpus, NPs also exhibited the extensive use of embedded phrasal structures as a different type of grammatical complexity from the more traditional view which equated complexity with dependent clauses. This is particularly relevant in the CMSC, where nominal premodification favours simple parataxis while it increases meaning-inferring processes.

As for postmodification, Berlage (2014:47) and Biber et al. (1999:606) claimed that prepositional phrases are the most common types of post modifiers in all registers, ranging from 65 to $80 \%$ in all registers. In our data, however, we discovered a different trend, as prepositional phrases, found in $29.3 \%$ of the post-modifying slots, were not the most common post-modifier. Appositive nouns occurred in $39 \%$ of the instances analysed, by far the most common type of post-modification in the CMSC. This is in

Noguera, Y. \& Pérez-Paredes, P. (2018) Register analysis and ESP pedagogy: noun-phrase modification in a corpus of Military Navy submariners. English for Specific Purposes, https://doi.org/10.1016/j.esp.2018.06.002 
contrast with Biber et al (1999), who found appositions in around 15\% of the news and academic prose. In the CMSC, appositive noun phrases were frequently used to introduce an acronym, or to itemize the members of a group. In this study, these acronyms did not follow any fixed patterns or structure whereas Biber et al (2011) found that over $90 \%$ of all appositive constructions involved a proper noun (e.g. Mr. Trump, President), which is not common in the CMSC, where appositive NPs mainly

describe a device, whether this is a weapon or a submarine( see below examples 43-46 related to types of submarines and torpedoes). As suggested by Biber et al. (2011), our results confirm that appositive NPs are more common in non-fiction registers.

(45) (CMSC-2005) Test firings from a UK Royal Navy nuclear attack submarine (SSN) were in June 2005.

(46) (CMSC-2005) There is a reduced emphasis on antisubmarine warfare programmes $(A S W)$ in many parts of the world.

(47) (CMSC-2006) The failure of two torpedo tube-launched (TTL) Tomahawk Block IV developed test firings.

As in premodification, the nouns in the CMSC displayed a distinctive postmodification pattern. In particular, the low frequency of prepositional phrases in the postmodifier slot is of relevance. Historically, the prepositions in and on expressed concrete locative meaning (Biber \& Gray, 2016) and their use to express abstract meanings is quite recent. However, in the $\mathrm{CMSC}$, concrete meanings expressed by noun-modifying prepositional phrases are the most common maybe due to the fact that the nouns analysed were both tangible and their use fairly technical (e.g. the first two boats in the Military Navy submariners. English for Specific Purposes, https://doi.org/10.1016/j.esp.2018.06.002 
class). In our corpus, the prepositions in and of were the most common heads in postnominal phrases, which confirms Biber et al.'s (2016) finding that of, in and for as the most frequent in science research writing and the social sciences. However, the preposition for was less relevant in our data in terms of frequency.

Our findings about modification in NPs situate SE as being more similar to academic written registers than news prose (Biber et al., 1999), something not immediately apparent from the initial composition and sources of the texts which make up our corpus. CMSC texts, judging from the analysis of NPs, favour an informational, phrasal style that makes a dense use of nouns and phrasal modifiers ( Biber \& Gray, 2016). Similarly, our results revealed that specific nouns displayed distinct modification patterns, which suggests that a contextualized study of their syntactic contexts can only benefit students' understanding of SE. This approach is consistent with the findings in Laso-Martín (2009) and Walker (2011) who suggested that the study of individual syntactic patterns of a selection of nouns could be used to explore semantic preferences and attested uses in the language classroom. Biber et al ( 2016 ) claimed that by the end of the twentieth century, almost any noun could be used freely as a pre-modifier of another head noun, including an increased use of noun phrases with multiple premodifying nouns.

This could lead to a new lexical expansion in grammar and in meanings difficult to categorize but widely spread in our corpus even for specific tangible noun definitions (jet ski type boat).

5.2. Which areas of the NP behaviour analysed, if any, are of interest to SE language education? 
Using a corpus-driven approach, we could identify the most frequent nouns in CMSC as well as the modification behaviour in these noun phrases. In our study, the frequency of use of nouns as premodifiers was well above the average mean in most registers, which call for a specific treatment of this feature. In particular, we found that the texts which Navy submariners are exposed to are of great complexity as embedded phrasal structures allow for a lack of explicitness and dense packaging at the NP level ( Biber et al., 1999) which is uncommon in other registers. According to Biber\&Gray (2016: 245) noun phrasal complexity is "more complex from a processing perspective than alternative structures with dependent clauses".

Biber \& Gray (2016) highlight that phrasal complexity features such as those found in our research tend to be highly specialized, normally found in (science) research writing. This finding is of great interest to language teachers and material developers, who, in the context of the CMSC and SE may need to focus their attention academic, scientific English features. The fact that our corpus is made up of magazine texts should not therefore mislead us into assuming that news register features should prevail over academic English, as shown by the behaviour of the NP in our corpus.

The kind of phrasal complexity in the CMSC is characterized by above-the-average frequency of noun + noun premodification, low adjectival premodification, heavy appositional postmodification as well as low prepositional phrase postmodification. Nouns such as class, missile or system display an unusual high percentage of noun premodifiers. The co-occurrence of these nouns with heavy embedded premodification contributes to a type of complexity which is not usually found in non-specialised registers. The study of lexico-grammatical patterns around nouns such as system (Target

Noguera, Y \& \& Pérez-Paredes, P. (2018) Register analysis and ESP pedagogy: noun-phrase modification in a corpus of English fo Military Navy submariners. English for Specific Purposes, https://doi.org/10.1016/j.esp.2018.06.002 
acquisition system) and attention to $\mathrm{N}+\mathrm{N}+(\mathrm{N})$ are certainly of interest for Navy submariners. The second and third most common type of premodifiers in our corpus study is attributive adjectives (mainly classifiers) and -ed participles. Some of these participles are unquestionably specific and infrequent in other texts, formed by a hyphenated-noun and a past participle premodifying a noun (e.g. wire-guided torpedo). Cortes (2004) has suggested that explicit teaching of lexical associations like the ones above are necessary to promote language noticing and awareness of otherwise not so salient features in general English.

According to Pastor-Gomez (2009), the choice between pre-and -postmodification is made by the distinction between explicitness and non-explicitness of the information provided by the NP and the specific communicative goals. In our corpus study, the first type of postmodifiers is NPs, represented by appositive noun phrases, providing the head noun with descriptive information. They can be found mainly as acronyms while the second type of postmodification is represented by prepositional phrases. SE students should be aware of these syntactic properties to understand professional texts and, particularly, be able to interpret and use appositive noun phrases.

Parkinson and Musgrave (2014) highlighted the need to study noun modification in the light of specialized corpus-driven data rather than general English of general purpose corpora. The NP data of our corpus shed some light about lexical, syntactic and functional patterns, which once studied and classified, can be integrated into a learning/teaching ESP course.

In a similar vein, Henry and Roseberry (2001) also emphasized the importance of corpus-data analysis by language instructors as the mere exposure to the patterns without guidance is not likely to present pedagogic challenges to learners (Author, Military Navy submariners. English for Specific Purposes, https://doi.org/10.1016/j.esp.2018.06.002 
2010; Author et al., 2011).

Special attention needs to be paid to some NPs in CMSC with the highest percentages $(>80 \%)$ of nominal premodification represented by the nouns class and missile. Concordances of the noun class identified as significant in our corpus can provide excellent opportunities for the elaboration of data-driven learning (DDL) activities that consider that, for example, most of the nouns premodifying class are places (Los Ángeles class, Virginia class, Ohio).

Another useful DDL application of our corpus may focus on appositional nouns. Considering that missile has the highest instances of apposition nouns $(87.50 \%)$, identifying relevant concordances can be of interest to NS learners. Some target items include the acronyms that appear in appositional position such as Advanced medium range air- to- air missile (AMRAAM), Intercontinental ballistic missiles (ICBMs) or Fibre optic guided missile (FOGM). This is a unique feature of this register and, accordingly, deserves attention.

Despite the fact that most ESP studies confirm adjectives as the most frequently premodifier in specialized discourses (Maniez,2012), attention can be paid to the

classifiers in our data. These can present submariners with opportunities to interact with the range of lexical choices in NPs. Likewise, activities exploiting postmodifying appositions, certainly infrequent in other registers, are necessary to frame the specific nature of NP complexity in this register.

\section{Conclusion}

Our research has shown that judging a register by its publication format, journal/magazines in our case, may be misleading in terms of the pedagogical

Noguera, Y. \& Pérez-Paredes, P. (2018) Register analysis and ESP pedagogy: noun-phrase modification in a corpus of English for Military Navy submariners. English for Specific Purposes, https://doi.org/10.1016/j.esp.2018.06.002 
implications which may derive from a closer look at how language is used. However, it is necessary to highlight that this study presents limitations in terms of the nature of the corpus and the object of our analysis. While CMSC includes curated texts by the Spanish Ministry of Defence over a decade, it fails to include classified material which cannot be accessed by researchers. In this way, its textual typology is constrained by the non-classified nature of the data collected and the range of nouns analysed. For example, our pool of nouns represents $11 \%$ of all occurrences of the NN1 POS tag (singular common noun). Those nouns in singular occurring in CSMC fewer than 10 times are 7,027 in total and represent $87 \%$ of all the occurrences. Given their low frequency of occurrence, these nouns were not analysed. Second, this study has looked at NP modification. Future research may need to establish the status of verb phrases complexity in CMSC in order to paint a more complete picture of the register features of this corpus.

CMSC was compiled as a response to the lack of research and teaching/learning materials in Submarine English and Maritime English for Navy submariners. This corpus will allow future research efforts that try to capture the nature of the language needed by professional Navy submariners for the training and future careers, and hopefully will serve as the basis for training initiatives that integrate DDL pedagogic principles.

\section{References}


Altenberg, B. (1982). The genitive v. the of-construction: A study of syntactic variation in 17th century English. Gleerup.

Berlage, E. (2015). Noun Phrase Complexity in English. https://doi.org/10.1017/CBO9781139057684

Biber, D., \& Gray, B. (2015). Grammatical complexity in academic English: Linguistic change in writing. (Cambridge).

Biber, D., Grieve, J., \&Iberri-Shea, G. (2009). Noun phrase modification. One Language, Two Grammars?: Differences Between British and American English, 182-193. https://doi.org/10.1017/CBO9780511551970.010

Biber, D., Johansson, S., Leech, G., Conrad, S., \&Finegan, E. (1999). Longman grammar of spoken and written English. Tesol Quarterly. https://doi.org/10.2307/3587792

Biber, D. (2003). Compressed noun-phrase structures in newspaper discourse: The competing demands of popularization vs. economy. New Media Language, 169181.

Biber, D., \& Clark, V. (2002). Historical shifts in modification patterns with complex noun phrase structures. Teresa Fanego, Maria López-Couso and Javier PerezGuerra (Eds.). English Historical Morphology. Selected Papers from, 11, 43-66.

Biber, D., \& Conrad, S. (2009). Register, genre, and style. Cambridge University Press.

Biber, D., \& Gray, B. (2010). Challenging stereotypes about academic writing:

Complexity, elaboration, explicitness. Journal of English for Academic Purposes, 9(1), 2-20. https://doi.org/10.1016/j.jeap.2010.01.001

Biber, D., \& Gray, B. (2016). Grammatical complexity in academic English: Linguistic change in writing. Cambridge University Press.

Biber, D., \& Gray, B. (2011). Grammatical change in the noun phrase: the influence of written language use. English Language and Linguistics, 15(2), 223-250. https://doi.org/10.1017/S1360674311000025

Blakey. (1987). English for Maritime Studies. Cambridge: Prentice Hall International.

Bocanegra-Valle, A. (2013). Maritime English. The Encyclopedia of Applied Linguistics.

Chung, T. M., \& Nation, P. (2003). Technical vocabulary in specialized texts. Reading in a Foreign Language, 15(2), 103.

Cole, C., Pritchard, B., \&Trenkner, P. (2007). Maritime English instruction - ensuring instructors' competence. Ibérica, 14, 123-148. 
Cole, C., \&Trenkner, P. (2012). Whither Maritime English?--2012. International Maritime Lecturers Association (IMLA), 3.

Cole, C., \&Trenkner, P. (2008). The yardstick for maritime English STCW assessment purposes. In Proceedings of IMLA 16th Conference (pp. 163-173).

Cortés, V. (2004). Lexical bundles in published and student disciplinary writing: Examples from history and biology. English for Specific Purposes, 23((4)), 397423.

Curado Fuentes, A. (2006). A Corpus-Based Focus on ESP Teaching. Teaching English with Technology: A Journal for Teachers of English, 6(4), 0.

De Haan, P. (1989). Postmodifying clauses in the English noun phrase: A corpus-based study. Rodopi.

Del Pozo Triviño, M. (2011). Analysis Framework for Translation of Maritime Legal Documents. Research in Language, 9(1), 95-110.

Flowerdew, J., \& Peacock, M. (2001). Research Perspectives on English for Academic Purposes. https://doi.org/10.1017/CBO9781139524766

Gavioli, L. (2005). Exploring Corpora for ESP Learning. John Benjamins Publishing.

Ghadessy, M., Henry, A., \& Roseberry, R. L. (2001). Small corpus studies and ELT: Theory and practice (Vol. 5). John Benjamins Publishing.

Glover, A., Johnson, E., Strevens, P., \& Weeks, F. (1988). SeaSpeak training manual.

Greenbaum, S., Quirk, R., Leech, G., \&Svartvik, J. (1985). A comprehensive grammar of the English language. USA: Longman. Retrieved November, 4, 2012.

Huddleston, R., Pullum, G. K., \& others. (2002). The Cambridge grammar of English. Language. Cambridge: Cambridge University Press, 1-23.

Hutter, J. A. (2015). A Corpus Based Analysis of Noun Modification in Empirical Research Articles in Applied Linguistics (Doctoral dissertation, Portland State University).

IMO. (2001). Imo standard marine communication phrases (SMCP).

International Maritime Organization. (2001). Final Act of the Conference of Parties to the International Convention on Standards of Training, Certification and Watchkeeping for Seafarers (STCW), 1978.

Kilgarriff, A., Kovávr, V., Rychlý, P., \&Suchomel, V. (2014). Finding Terms in Corpora for Many Languages with the Sketch Engine. Proceedings of the Demonstrations at the 14th Conference of the European Chapter of the Association

Noguera, Y. \& Pérez-Paredes, P. (2018) Register analysis and ESP pedagogy: noun-phrase modification in a corpus of English for Military Navy submariners. English for Specific Purposes, https://doi.org/10.1016/j.esp.2018.06.002 
for Computational Linguistics, 53-56. Retrieved from

http://www.aclweb.org/anthology/E14-2014

Kluijven, P. C. (2003). The international maritime language programme. An English Course for Students at Maritime Colleges and for on-Board Training, Alk \& Heijnen Publishers, Alkmaar, The Netherlands.

Laso- Martín, N.J. (2009). A corpus-based study of the phraseological behavior of abstract nouns in medical English. A Needs Analysis of a Spanish medical community. 5th Corpus Linguistics. University of Barcelona.

Leech, G., Hundt, M., Mair, C., \& Smith, N. (2009). Change in contemporary English: a grammatical study. https://doi.org/10.1017/CBO9780511642210

NATO. (2016). 6001 Stanag (Edition 5): Language Proficiency Levels. In Brussels, 2016.

Orna-Montesinos, C. (2016). Intercultural Communication in the Military: A Resource Pack for the ESP Teacher. LAP Lambert Academic Publishing. Retrieved from https://books.google.es/books?id=ulxRvgAACAAJ

Parkinson, J., \& Musgrave, J. (2014). Development of noun phrase complexity in the writing of English for Academic Purposes students. Journal of English for Academic Purposes, 14, 48-59. https://doi.org/10.1016/j.jeap.2013.12.001

Pastor- Gómez, I. (2010). Nominal Modifiers in Noun Phrase Structure: Evidence from Contemporary English. (University of Santiago).

Pritchard, B. (2002). On Some Issues in the Standardization of Maritime EnglishPedagogical Implications. In proceedings of International Seminar on Maritime English, Istanbul Technical University.

Pritchard, B. (2003). Maritime English syllabus for the modern seafarer: Safety-related or comprehensive courses? WMU Journal of Maritime Affairs, 2(2), 149-166.

Rosenbach, A. (2007). Emerging variation: determiner genitives and noun modifiers in English. English Language and Linguistics, 11(1), 143-189.

Seafarers Centre. (1996). The MARCOM Project Final Report. In Funding: European (4th RTD Framework Programme) (Ed.) (Vol. 1).

Strevens, P., \& Weeks, F. F. (1984). Seaspeak reference manual. Pergamon.

Swales, J. (1990). Genre analysis: English in academic and research settings. Cambridge University Press. 
Tick, A. (2006). A Web-based E-learning Application of Self Study Multimedia Programme in Military English. Proceedings of the 3rd Romanian-Hungarian Joint Symposium on Applied Computational Intelligence, 25-26.

Tognini-Bonelli, E. (2001). Corpus linguistics at work (Vol. 6). John Benjamins Publishing.

Trenkner, P. (2000). Maritime English. An attempt of an imperfect definition. In Proceedings of the 2nd IMLA Workshop on Maritime English in Asia (pp. 1-8).

Varantola, K. (1993). Modification of nouns by nouns-bad by definition? Anglistik Und Englishunterricht, 49, 69-83.

Walker, C. (2011). How a corpus-based study of the factors which influence collocation can help in the teaching of business English. English for Specific Purposes, 30(2), 101-112. https://doi.org/10.1016/j.esp.2010.12.003

Weeks, F. (1988). Seaspeak training manual. Pergamon. 